\title{
The use of fermented buckwheat to produce L-carnitine enriched oyster mushroom
}

\author{
Tae-kyung Lee ${ }^{1}$, Thi Thanh Hanh Nguyen², Namhyeon Park', So-Hyung Kwak', Jeesoo Kim', Shina Jin', \\ Gyu-Min Son ${ }^{1}$, Jaewon Hur ${ }^{1}$, Jong-In $\mathrm{Choi}^{3}$ and Doman Kim ${ }^{1,2^{*}}$ (D)
}

\begin{abstract}
L-Carnitine is an essential compound that shuttles long chain fatty acids into mitochondria. The objective of this study was to produce L-carnitine enriched oyster mushroom (Pleurotus ostreatus) using common buckwheat fermented by Rhizopus oligosporus. Mushroom grown on common buckwheat medium contained 9.9-23.9\% higher L-carnitine $(186.3 \mathrm{mg} / \mathrm{kg})$ than those grown on basal medium without any buckwheat addition. Those grown on fermented common buckwheat medium contained the highest L-carnitine content $(201.2 \mathrm{mg} / \mathrm{kg})$. Size index and lightness of mushroom pileus $\left(L^{*}\right)$ were also the highest (100.7 and 50.6, respectively) for those grown in medium added with fermented common buckwheat (20\%, w/w). Antioxidant activities of both mushroom extracts $(1.5 \mathrm{mg} / \mathrm{mL})$ showed the same level as $38.7 \%$ for mushroom grown in media added with common buckwheat or fermented common buckwheat. At the treatment concentration of $300 \mu \mathrm{g} / \mathrm{mL}$, viabilities of murine macrophage cell line Raw 264.7 cells treated with ethanol extract of oyster mushroom grown on buckwheat medium ranged from 58.9 to $67.8 \%$. The oyster mushroom grown on buckwheat and fermented buckwheat medium can be used as one of the substitutes for meat based diets.
\end{abstract}

Keywords: Antioxidant, Cell cytotoxicity, Functional food, Phenolic compounds, Oyster mushroom, Buckwheat

\section{Introduction}

Mushroom has been used as traditional foods and medicine in eastern Asia due to its functional properties. World production of mushroom has been grown rapidly since late 20th century. China accounted for over $70 \%$ of world production of mushroom in 2016 (FAOSTAT 2016). Pleurotus ostreatus, the second most cultivated mushroom in the world, is commonly known as "Oyster mushroom" and "Hiratake" (Sánchez 2010). Oyster mushroom has various biological functions, including antimicrobial activity against Escherichia coli, and Staphylococcus aureus (Akyuz et al. 2010), antineoplastic activity against Ehrlich ascetic tumor (Wolff et al.

\footnotetext{
*Correspondence: kimdm@snu.ac.kr

${ }^{1}$ Graduate School of International Agricultural Technology

and Center for Food and Bioconvergence, Seoul National University,

Pyeongchang 25354, South Korea

Full list of author information is available at the end of the article
}

2008), antioxidant activity (Venkatakrishnan et al. 2009), antitumor activity of $P$. ostreatus mycelia-derived proteoglycans (Sarangi et al. 2006), and immunomodulatory activity of pleuran, an insoluble polysaccharide extracted from P. ostreatus (Jesenak et al. 2013). Yields and chemical composition of mushroom are enhanced by adding essential elements such as selenium (da Silva et al. 2012; Kristensen et al. 2012; Vieira et al. 2013).

Among buckwheat species, common buckwheat (Fagopyrum esculentum) and Tartary buckwheat (Fagopyrum tataricum) are cultivated for human food. Buckwheat (Fagopyrum spp.) is a good source of nutritionally valuable amino acids, dietary fibers, and minerals such as zinc and copper (Bonafaccia et al. 2003; Zhang et al. 2012). In addition, buckwheat has been found to contain flavonoids, fagopyrin, tocopherols and phenolic substances such as 3-flavanols, rutin, phenolic acids, and their derivatives with antioxidant activity (Fabjan et al. 2003; Jiang 
et al. 2007). Also, buckwheat has higher content of amino acids such as methionine and lysine (precursors of L-carnitine) than rice and other pseudo cereals (Bonafaccia et al. 2003; Mota et al. 2016). L-Carnitine ( $\beta$-hydroxy- $\gamma$ $N$-trimethylaminobutyric acid) is a non-essential amino acid derivative and natural compound occurring most in red meat (Demarquoy et al. 2004). Its major role is a carrier of long chain fatty acid into mitochondria for beta-oxidation. L-carnitine is considered as a weight-loss product because of its function related to fat metabolism. Clinical studies have shown that regular L-carnitine intake can lead to weight loss in human (Novakova et al. 2016). Although L-carnitine is synthesized from essential amino acids, lysine and methionine in human, 75\% of $\mathrm{L}$-carnitine is exogenously obtained from food, especially meat and milk (Steiber et al. 2004). However, there have been many controversies regarding meat based diets for human health issue (Chao et al. 2005; Pan et al. 2011; Wang and Beydoun 2009), since most L-carnitine is supplied from meat based diet, vegetarians have to eat more plants to have enough intake of $\mathrm{L}$-carnitine (Cave et al. 2008; De Vivo and Tein 1990). Buckwheat without additional nutrients has been fermented using Rhizopus oligosporus ( $R$. oligosporus), producing four times higher amount of L-carnitine than original buckwheat (Park et al. 2017). The fermented buckwheat extract powder with increased amounts of L-carnitine was used as a complex additive in poultry feed to Hy-Line brown hens and resulted higher egg production and quality than the control group, and increased the L-carnitine content in the yolk (Park et al. 2017). Therefore, in this study, we focus on the utilization of buckwheat and fermented buckwheat as medium materials to improve the biological activity of oyster mushroom. In addition, the morphological characteristics, L-carnitine content, antioxidant properties, and cell cytotoxicity of oyster mushroom were investigated.

\section{Materials and methods}

\section{Microorganisms and culture condition}

Rhizopus microspores var. oligosporus ( $R$. oligosporus) was obtained from our previous study (Park et al. 2017) and deposited as KCCM 11948P (Korean Culture Center of Microorganisms, Seoul, Korea). R. oligosporus was maintained on potato dextrose agar (PDA) (Difco, USA) and incubated at $28^{\circ} \mathrm{C}$ until spore formation (Park et al. 2017). P. ostreatus was obtained from Mushroom Research Institute (Gwangju, Gyeonggi, Korea) (Choi et al. 2013).

\section{Preparation of fermented buckwheat}

Tartary buckwheat and common buckwheat were purchased from Bongpyeong (Pyeongchang bongpyeong memil, Gangwon-do, Korea). Fermented buckwheat was prepared with a modified method described previously (Park et al. 2017). Briefly, unhulled buckwheat (750 g) was soaked in water $(1.5 \mathrm{~L})$ for $6 \mathrm{~h}$ in a metal tray (height $\times$ width $\times$ length $=5.5 \mathrm{~cm} \times 15.5 \mathrm{~cm} \times 28.5 \mathrm{~cm})$ and sterilized at $121{ }^{\circ} \mathrm{C}$ for $25 \mathrm{~min}$. Then $7.5 \mathrm{~mL}$ of $R$. oligosporus spore solution $\left(1 \times 10^{6}\right.$ spores $\left./ \mathrm{mL}\right)$ was inoculated into each sterilized buckwheat tray after cooling to room temperature followed by incubation at $30{ }^{\circ} \mathrm{C}$ until mycelia covered the surface of tray $(76 \mathrm{~h})$ with relative humidity maintained above $90 \%$. Fermented buckwheat was lyophilized at -10 to $0{ }^{\circ} \mathrm{C}$ under $10 \mathrm{~Pa}$ for 4 days (Eyela, Tokyo, Japan). It was then milled with a blender (Hanil, Seoul, Korea) and stored at $-20{ }^{\circ} \mathrm{C}$ blocking light to preserve sensitive compounds such as quercetin and rutin for further analysis.

\section{Analyses of fermented buckwheat}

Total phenolic content (TPC) of buckwheat was measured with Folin-Ciocalteu method (Singleton et al. 1999). Buckwheat and fermented buckwheat were suspended in $70 \%$ ethanol at $50 \mathrm{mg} / \mathrm{mL}$ and the supernatant was separated by centrifugation at $13,500 \times g$ for $10 \mathrm{~min}$. The supernatant, diluted fivefold with water $(120 \mu \mathrm{L})$ was then mixed with $15 \mu \mathrm{L}$ of Folin-Ciocalteu reagent for $3 \mathrm{~min}$ on a microplate shaker $(300 \mathrm{rpm}$, Thermo Fisher Scientific, Waltham, MA, USA). Then $15 \mu \mathrm{L}$ of $10 \%$ (w/v) $\mathrm{Na}_{2} \mathrm{CO}_{3}$ was added to the mixture followed by shaking for $30 \mathrm{~min}$. TPC was determined at wavelength of $760 \mathrm{~nm}$ with a microplate reader (Molecular Devices, Sunnyvale, CA, USA) using gallic acid as standard (10 to $100 \mu \mathrm{g} / \mathrm{mL}$ ). Total flavonoids content (TFC) of the extract was measured using aluminum chloride method (Chang et al. 2002). The supernatant, diluted fivefold with methanol $(2 \mathrm{~mL})$ was then mixed with $10 \%(\mathrm{w} / \mathrm{v}) \mathrm{AlCl}_{3}$ $(100 \mu \mathrm{L})$ dissolved in water and $0.1 \mathrm{mM}$ Potassium acetate $(100 \mu \mathrm{L})$. TFC was then determined at wavelength of $415 \mathrm{~nm}$ using quercetin as the standard (10 to $100 \mu \mathrm{g} /$ $\mathrm{mL})$.

\section{Mushroom spawning and fruiting in field scale}

Cultivation of $P$. ostreatus was performed using previously reported procedure (Lee et al. 1999) with slight modification. Briefly, P. ostreatus was pre-cultured on substrate mixture composed of $80 \%$ Douglas-fir sawdust and $20 \%$ rice bran packaged in heat-resistant bottle $(1100 \mathrm{~mL}, \phi 75 \mathrm{~mm})$ at $20{ }^{\circ} \mathrm{C}$ for 30 days. After mycelium was totally grown, $4 \mathrm{~g}$ of hyphae attached substrate was transferred into each buckwheat medium. The buckwheat medium contained milled unhulled buckwheat seeds in basal medium containing $66.7 \%(\mathrm{w} / \mathrm{w})$ poplar saw dust, $16.7 \%(\mathrm{w} / \mathrm{w})$ cotton-seed meal, and $16.7 \%$ $(\mathrm{w} / \mathrm{w})$ beet pulp. Moisture content was adjusted to $65 \%$ 
Table 1 Composition and ratio of mushroom medium

\begin{tabular}{|c|c|c|c|c|c|c|c|c|c|c|}
\hline \multirow[t]{3}{*}{ Medium } & \multicolumn{7}{|c|}{ Medium composition (g/bottle) } & \multirow{3}{*}{$\begin{array}{l}\text { Medium weight } \\
\text { per bottle }(g)\end{array}$} & \multirow{3}{*}{$\begin{array}{l}\text { Buckwheat } \\
\text { proportion } \\
\text { to medium }(\% \text {, } \\
w / w)\end{array}$} & \multirow{3}{*}{$\begin{array}{l}\text { Buckwheat } \\
\text { proportion } \\
\text { to total medium } \\
\text { weight }(\%, w / w)\end{array}$} \\
\hline & \multirow{2}{*}{$\begin{array}{l}\text { Poplar saw } \\
\text { dust }\end{array}$} & \multirow{2}{*}{$\begin{array}{l}\text { Cotton seed } \\
\text { meal }\end{array}$} & \multirow[t]{2}{*}{ Beet pulp } & \multicolumn{4}{|c|}{ Buckwheat } & & & \\
\hline & & & & CB & FCB & TB & FTB & & & \\
\hline G & 144.7 & 36.2 & 36.2 & - & - & - & - & 620 & 0 & 0 \\
\hline CB & 135.3 & 33.8 & 33.8 & 14.0 & - & - & - & 620 & 20.74 & 2.26 \\
\hline FCB & 135.3 & 33.8 & 33.8 & - & 14.0 & - & - & 620 & 20.74 & 2.26 \\
\hline TB & 135.3 & 33.8 & 33.8 & - & - & 14.0 & - & 620 & 20.74 & 2.26 \\
\hline FTB & 135.3 & 33.8 & 33.8 & - & - & - & 14.0 & 620 & 20.74 & 2.26 \\
\hline
\end{tabular}

$G$ basal medium, $C B$ common buckwheat, FCB fermented common buckwheat, TB tartary buckwheat, FTB fermented tartary buckwheat

(w/w) before sterilization. Each milled buckwheat was mixed with basal medium at $20 \%(\mathrm{w} / \mathrm{w})$ of nutritious substrate. The following media were prepared: basal (G) medium, common buckwheat (CB) medium, fermented common buckwheat (FCB) medium, tartary buckwheat (TB) medium, and fermented Tartary buckwheat (FTB)

Total Size Index $=\frac{(\text { Mushroom weight } \times \text { Pileus diameter } \times \text { Stipe length } \times \text { Stipe thickness })}{100}$
Minolta, Tokyo, Japan). Total size index (TSI) representing comprehensive morphological size was each morphological value. Each value was obtained by multiplication of weight $(\mathrm{g})$, pileus diameter $(\mathrm{cm})$, stipe length $(\mathrm{cm})$, and stipe thickness $(\mathrm{cm})$. Each obtained value was then rescaled (divided by 100) and its unit was omitted using the following equation: medium (Table 1). All media (620 g) were packed in heatresistant bottle and sterilized serially at $100{ }^{\circ} \mathrm{C}$ for $30 \mathrm{~min}$ and $121{ }^{\circ} \mathrm{C}$ for $90 \mathrm{~min}$. After sterilization, each medium was cooled down to room temperature. Pre-cultured P. ostreatus (4 $\mathrm{g}$ of wet weight) was then inoculated to each medium and incubated at $20{ }^{\circ} \mathrm{C}$ under $65 \%$ relative humidity in a dark room. Carbon dioxide was controlled to be 3000 to $5000 \mathrm{ppm}$ to induce balanced shape of pileus and stipe (Sánchez 2010). After 30 days of incubation with mycelium to induce fruit body, old spawn was removed and temperature was maintained at $15{ }^{\circ} \mathrm{C}$. Relative humidity and carbon dioxide were maintained over $90 \%$ and $500-3000$ ppm, respectively. Each bottle possessed $0.056 \mathrm{~m}^{3}$ of space in the incubation room. On the 8th day after inducing fruit body, fruit bodies were harvested and 10 fruit bodies of each group were randomly selected. These fruit bodies were then lyophilized and stored at $-80^{\circ} \mathrm{C}$ for further analysis.

\section{Mushroom morphological characteristics}

Morphological characteristics such as fruit body weight, pileus diameter, and stipe length were determined. Halogen lamb analyzer MB35 (Ohaus Inc., Parsippany, NJ, USA) was used to measure moisture content of fruit body. Color change of mushroom pileus was measured with Hunter's color value ( $L^{*}$ (ligh vs dark), a* (red vs green), $b^{*}$ (yellow vs blue)) with a colorimeter (Konica

\section{Liquid chromatography analyses of mushroom components}

L-carnitine content in buckwheat and mushroom was analyzed with liquid chromatography-electrospray ionization-tandem mass spectrometry (LC-ESI-MS) (Park et al. 2017). Each sample (100 mg) was extracted with water $(1 \mathrm{~mL})$ and centrifuged at $13,500 \times g$ for $10 \mathrm{~min}$. The supernatant was diluted tenfold with acetonitrile. It was centrifuged again at $13,500 \times g$ for $10 \mathrm{~min}$. The supernatant was filtered using $0.2 \mu \mathrm{m}$ pore size syringe filter (Sartorius, Germany). For quercetin and rutin analysis, each sample $(100 \mathrm{mg})$ was extracted with $70 \%$ ethanol $(1 \mathrm{~mL})$ followed by centrifugation and filtration as described above.

The filtrate $(1 \mu \mathrm{L})$ was used for component analysis as follows. L-carnitine analysis was performed on an Acquity UPLC system equipped with ESI-MS and BEH $1.7 \mu \mathrm{m}$ HILIC column $(2.1 \mathrm{~mm} \times 150 \mathrm{~mm}$, Waters, USA). Mobile phase A was $15 \mathrm{mM}$ ammonium formate with $0.1 \%(\mathrm{v} / \mathrm{v})$ formic acid. Mobile phase B was acetonitrile with $0.1 \%$ (v/v) formic acid. Flow rate was set at $0.4 \mathrm{~mL} / \mathrm{min}$. Sample manager temperature was sustained at $20{ }^{\circ} \mathrm{C}$ while column temperature was maintained at $40{ }^{\circ} \mathrm{C}$. Mobile phase A was sustained at $10 \%$ for initial $3 \mathrm{~min}, 30 \%$ for the next $2 \mathrm{~min}, 60 \%$ for $1 \mathrm{~min}$, and $10 \%$ for the last $4 \mathrm{~min}$. Each compound was recorded and quantified at specific ion mass $\left[\mathrm{M}+\mathrm{H}^{+}\right]$. ESI-MS conditions were: ion mode, 
positive; capillary voltage, $+1.5 \mathrm{kV}$; cone voltage, $-10 \mathrm{~V}$; and single ion recording, $162 \mathrm{~g} / \mathrm{mol}$. Quercetin and rutin were separated using Kromasil $1.8 \mu \mathrm{m}$ C18 UHPLC column $(2.1 \mathrm{~mm} \times 50 \mathrm{~mm}$, Kromasil, Bohus, Sweden). Flow rate was set at $0.3 \mathrm{~mL} / \mathrm{min}$. Mobile phase A was $0.1 \%(\mathrm{v} / \mathrm{v})$ each mixture was obtained at wavelength of $517 \mathrm{~nm}$ on a microplate. DMSO solution was used as negative control. Trolox was used as a positive control.

The relative radical scavenging activity (SC) was obtained with the following equation (Choi et al. 2018a, b):

$$
\mathrm{SC}(\%)=\frac{(\text { Abs of negative control }- \text { Abs of the sample })}{\text { Abs of negative control }} \times 100
$$

formic acid while mobile phase B was acetonitrile with $0.1 \%(\mathrm{v} / \mathrm{v})$ formic acid. Temperature was set the same as described above. Mobile phase B was gradually increased from 30 to $100 \%$ in the initial $5 \mathrm{~min}$. It was then decreased back to $30 \%$ in the last $3 \mathrm{~min}$. ESI-MS conditions were: capillary voltage, $+1.5 \mathrm{kV}$; cone voltage, $+25 \mathrm{~V}$ for rutin and $-10 \mathrm{~V}$ for quercetin; single ion recording, $609.5 \mathrm{~g} /$ $\mathrm{mol}$ for quercetin and $303.2 \mathrm{~g} / \mathrm{mol}$ for rutin. All the samples, quercetin and rutin standards kept in amber glass vial, which blocked penetration of light.

The calibration curve was prepared by the external standard method, with L-carnitine standard ranging from 0.0125 to $0.5 \mu \mathrm{g} / \mathrm{mL}$ and quercetin ranging from 0.05 to $2 \mu \mathrm{g} / \mathrm{mL}$ and rutin ranging 0.1 to $5 \mu \mathrm{g} / \mathrm{mL}$. Each standard curves showed over 0.99 coefficient of determination $\left(R^{2}>0.99\right)$.

\section{Preparation of mushroom fruit body extract}

Powdered mushroom fruit body $(1 \mathrm{~g})$ of each treatment (G, CB, FCB, TB, and FTB medium) was extracted with ethanol $(10 \mathrm{~mL})$ at $20^{\circ} \mathrm{C}(200 \mathrm{rpm})$ for $24 \mathrm{~h}$. The mixture was then centrifuged at $3500 \times g$ for $10 \mathrm{~min}$. The supernatant was filtered using Whatman paper filter No. 1 (Whatman, Piscataway, NJ, USA). The filtrate was evaporated at $45^{\circ} \mathrm{C}$ for $1 \mathrm{~h}$ and lyophilized using a freeze dryer (Eyela, Tokyo, Japan). The yield of extracted mushroom by ethanol was $17.2 \%(\mathrm{w} / \mathrm{w})$. The extracted mushroom powder by ethanol was then re-dissolved in dimethyl sulfoxide (DMSO) solution $(10 \mathrm{mg} / \mathrm{mL})$ and used for in vitro cell cytotoxicity and antioxidant assays.

\section{Antioxidant activity of mushroom fruit body extract}

Antioxidant activity of mushroom ethanol extract was evaluated using 2,2-diphenyl-1-picrylhydrazyl (DPPH) radical scavenging method described previously (Nguyen et al. 2017) with slight modification. Mushroom powder was extracted by ethanol, then ethanol was removed by evaporation and lyophilized at -10 to $0{ }^{\circ} \mathrm{C}$ under $10 \mathrm{~Pa}$ (Eyela FD-550, Tokyo Rikakikai Co., Tokyo, Japan). The extracted mushroom powder was dissolved in DMSO and mixed with $100 \mu \mathrm{M}$ of DPPH reagent dissolved in ethanol. The final concentration of mushroom extract ranged from 0.01 to $1 \mathrm{mg} / \mathrm{mL}$. The mixture was incubated at room temperature for $30 \mathrm{~min}$. The absorbance of
Results were expressed as mean \pm standard error of the mean (SEM). All analyses were carried out in triplicates.

\section{Cell viability assay of oyster mushroom ethanol extract} Murine macrophage cell line Raw 264.7 cells (Raw 264.7 cells) were grown in Dulbecco's modified Eagle's medium supplemented with $10 \%$ fetal bovine serum (FBS, GenDEPOT, Barker TX, USA), 100 unit/mL penicillin (GenDEPOT, Barker TX, USA), and $100 \mu \mathrm{g} / \mathrm{mL}$ streptomycin (GenDEPOT, Barker TX, USA) at $37{ }^{\circ} \mathrm{C}$ under 5\% $\mathrm{CO}_{2}$ (Choi et al. 2018a, b; Maxwell et al. 2017). Extracted oyster mushroom powder was prepared in DMSO solution $(10 \mathrm{mg} / \mathrm{mL})$. RAW264.7 cells were seeded into 96-well cell culture plate at density of $2 \times 10^{4}$ cells/well and incubated at $37{ }^{\circ} \mathrm{C}$ for $24 \mathrm{~h}$ in a humidified atmosphere containing $5 \% \mathrm{CO}_{2}$. After discarding the culture medium, sample was then diluted with medium (1.17 to $1.2 \mathrm{mg} / \mathrm{mL}$ ) and added to each well followed by incubation at $37^{\circ} \mathrm{C}$ for $24 \mathrm{~h}$. To evaluate cytotoxicity, WST-1 (Water soluble tetrazolium salt) assay was performed using EZ-cytox kit (Daeil Lab service, Seoul, Korea).

\section{Statistical analysis}

All data were obtained after repeating the experiment three times except for morphological analysis. Morphological characteristics were obtained from 10 randomly selected samples. Mean value was given with standard error of the mean (SEM). The significant differences between groups were determined by Tukey's HSD (Honest significant difference) methods $(P<0.05$ or $P<0.01)$. Statistical analysis was performed using SPSS version 23.0 for Windows (SPSS Inc., Chicago, IL, USA).

\section{Results}

Levels of L-carnitine and phenolic compounds in fermented buckwheat

One $\mathrm{kg}$ of $\mathrm{CB}$ and TB contained $11.3 \mathrm{mg}$ and $6.2 \mathrm{mg}$ of L-carnitine, respectively (Table 2). After $R$. oligosporus fermentation, the amounts of L-carnitine in both buckwheats were increased (from $11.3 \mathrm{mg}$ to $26.2 \mathrm{mg}$ in $1 \mathrm{~kg}$ of FCB and from $6.2 \mathrm{mg}$ to $38.4 \mathrm{mg}$ in $1 \mathrm{~kg}$ of FTB). The increasing rate of $\mathrm{L}$-carnitine was higher after $\mathrm{TB}$ 
Table 2 L-carnitine, total phenolic content, quercetin and rutin concentration in buckwheat after $R$. oligosporus fermentation

\begin{tabular}{|c|c|c|c|c|}
\hline Buckwheat & L-carnitine $(\mathrm{mg} / \mathrm{kg})$ & $\begin{array}{l}\text { Total phenolic content (mg } \\
\text { GAE/kg) }\end{array}$ & Quercetin (mg/kg) & Rutin (mg/kg) \\
\hline$C B$ & $11.3 \pm 0.4$ & $1470.1 \pm 57.9$ & $19.3 \pm 0.4$ & $75.9 \pm 4.5$ \\
\hline FCB & $26.2 \pm 0.6^{* *}$ & $3466.8 \pm 102.6^{* *}$ & $14.7 \pm 0.8^{* *}$ & $71.4 \pm 2.0$ \\
\hline TB & $6.2 \pm 0.1$ & $5372.3 \pm 114.5$ & $3155.6 \pm 68.3$ & $3923.2 \pm 90.7$ \\
\hline FTB & $38.4 \pm 0.5^{* *}$ & $7279.3 \pm 176.2^{* *}$ & $2619.0 \pm 89.7^{* *}$ & $5148.1 \pm 188.5^{* *}$ \\
\hline
\end{tabular}

$C B$ common buckwheat, $F C B$ fermented common buckwheat, $T B$ tartary buckwheat, FTB fermented tartary buckwheat. TPC is expressed by garlic acid equivalent (GAE). Each mean value was written with standard error of the mean (SEM). For each parameter, asterisk star ( ${ }^{*}$ or $\left.{ }^{* *}\right)$ means significantly different $(p<0.05$ or $p<0.01)$ from non-fermented buckwheat

fermentation (619.4\%) than that after CB fermentation (231.8\%). Contents of total phenol and flavonoids in fermented buckwheat were higher than those of nonfermented buckwheat. However, content of quercetin decreased after fermentation in both $\mathrm{CB}$ and TB. On the contrary, rutin content in TB increased from 3923.2 to $5148.1 \mathrm{mg} / \mathrm{kg}$ after fermentation.

\section{Levels of L-carnitine in oyster mushroom in all samples}

Amounts of L-carnitine in $1 \mathrm{~kg}$ of dried oyster mushroom grown on different media $(\mathrm{CB}, \mathrm{FCB}, \mathrm{TB}$, and $\mathrm{FTB}$ medium) were compared. Results are shown in Table 3. When oyster mushroom was grown on FCB medium, the amount of $\mathrm{L}$-carnitine was significantly $(P<0.01)$ increased (by 22.3\%) compared to that grown on $G$ medium. However, oyster mushroom grown on FTB medium had smaller increase in the amount of L-carnitine (by $12.9 \%$ ) compared to that grown on $\mathrm{G}$ medium.

\section{Morphological characteristics of mushroom grown on buckwheat media}

Mushroom weight and moisture content were similar to each other for all samples. They were not significantly $(P>0.01)$ different compared to those of mushroom grown on $\mathrm{G}$ medium (Table 4). Mushroom size was represented by total size index (TSI). TSI of oyster mushroom grown on FCB medium was significantly $(P<0.01)$ increased compared to that grown on G medium. However, other size parameters such as pileus diameter, stipe length, and stipe thickness were not significantly changed except pileus diameter in FCB medium and stipe length in $\mathrm{CB}$ medium.

Color index of mushroom grown on buckwheat containing medium

By adding buckwheat into the media, Lightness ( $\left.\mathrm{L}^{*}\right)$ values of all mushroom samples were significantly increased $(P<0.01)$ compared to those grown on $\mathrm{G}$ medium (Table 4). Yellowness $\left(b^{*}\right)$ values were also increased for all mushrooms grown on media added with buckwheat. However, yellowness values of mushrooms grown on TB medium were not significantly $(P>0.01)$ different from those of mushrooms grown on $\mathrm{G}$ medium.

\section{Antioxidant activities of ethanol extracts of mushrooms}

Antioxidant effects of mushroom ethanol extracts against $\mathrm{DPPH}$ were evaluated at concentration ranging from 0.2 to $1.5 \mathrm{mg} / \mathrm{mL}$. Results are shown in Fig. 1. Radical scavenging activities of all samples were increased in a concentration-dependent manner. At final concentration of $1.5 \mathrm{mg} / \mathrm{mL}$, radical scavenging activity of oyster mushroom ethanol extract ranged from 25.9 to $38.7 \%$. At this concentration, ethanol extract of mushroom grown on $\mathrm{G}$ medium was found to be $25.9 \%$. Ethanol extracts of mushrooms grown on $\mathrm{CB}$ and FCB medium showed the same scavenging activity (both at $38.7 \%$ ). Those of mushrooms grown on TB and FTB medium showed scavenging activities of 28.7 and $30.9 \%$, respectively. Trolox used as positive control (Additional file 1: Figure S1).

Table 3 L-carnitine content in oyster mushroom grown on various buckwheat media

\begin{tabular}{|c|c|c|c|c|c|}
\hline $\begin{array}{l}\text { Mushroom medium } \\
\text { material }\end{array}$ & Mean $(\mathrm{mg} / \mathrm{kg})$ & Increase rate (\%) & $\begin{array}{l}\text { Mushroom medium } \\
\text { material }\end{array}$ & Mean (mg/kg) & $\begin{array}{l}\text { Increase } \\
\text { rate (\%) }\end{array}$ \\
\hline G & $164.5 \pm 4.9$ & & & & \\
\hline$C B$ & $186.3 \pm 8.1$ & 13.3 & $\mathrm{~TB}$ & $180.8 \pm 6.2$ & 9.9 \\
\hline FCB & $201.2 \pm 3.6^{* *}$ & 22.3 & FTB & $185.7 \pm 4.9$ & 12.9 \\
\hline
\end{tabular}

$G$ basal medium, $C B$ common buckwheat, $F C B$ fermented common buckwheat, $T B$ tartary buckwheat, FTB fermented tartary buckwheat. Each mean value was written with standard error of the mean (SEM). For each parameter, asterisk star $\left(^{*}\right.$ or $\left.{ }^{* *}\right)$ means significantly different $(p<0.05$ or $p<0.01)$ from basal medium (G) 


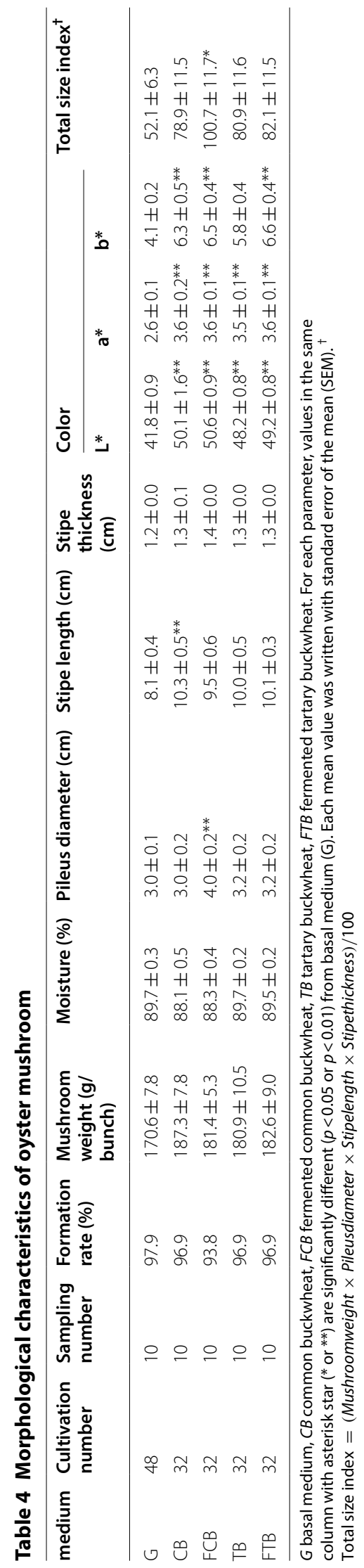




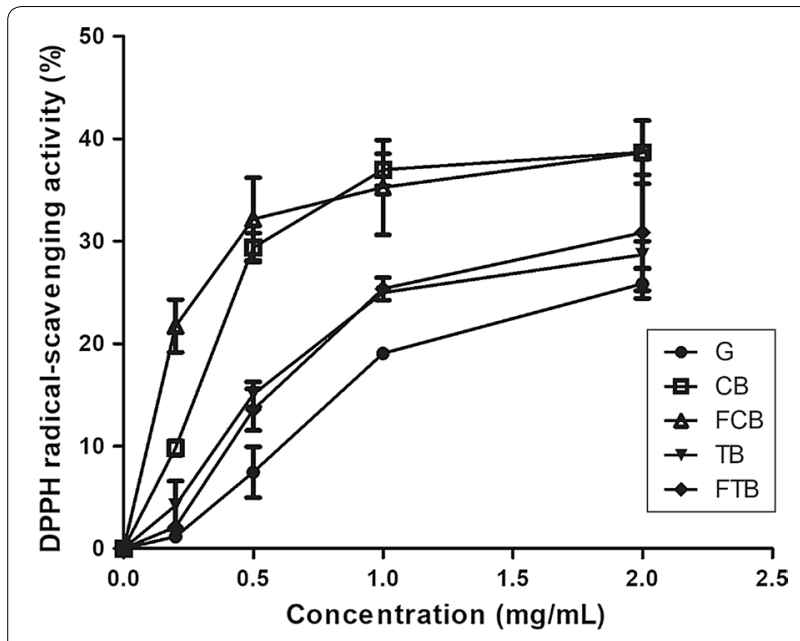

Fig. 1 DPPH radical scavenging activities of ethanol extract of oyster mushroom fruit body. $G$ basal medium, $C B$ common buckwheat medium, FCB fermented common buckwheat medium, TB tartary buckwheat medium, FTB Fermented Tartary buckwheat medium. Each mean value was written with standard error of the mean (SEM)

\section{Cell cytotoxicity ethanol extract of oyster mushroom against Raw 264.7}

Cytotoxicity of ethanol extract of mushroom fruit body to Raw 264.7 cells was evaluated at a final concentration ranging from 18.75 to $1200 \mu \mathrm{g} / \mathrm{mL}$ (Fig. 2). At a final concentration of 0 to $75 \mu \mathrm{g} / \mathrm{mL}$, viability of Raw 264.7 cells was above $90 \%$ after treatment with all ethanol extract samples. Up to $150 \mu \mathrm{g} / \mathrm{mL}$, the viabilities of Raw 264.7 cells treated with ethanol extracts of all mushroom samples were not significantly $(P>0.05)$ different from those of control cells without ethanol extract treatment. At final concentration of $300 \mu \mathrm{g} / \mathrm{mL}$, viabilities of cells treated with ethanol extract of oyster mushroom grown on buckwheat medium ranged from 58.9 to $67.8 \%$.

\section{Discussion}

In this study, the amounts of L-carnitine in FCB and FTB by $R$. oligosporus were increased 2.3 times and 6.2 times compared to $\mathrm{CB}$ and TB (Table 3 ). L-carnitine is synthesized from lysine and methionine (Bremer 1983), thus the synthesis of L-carnitine depends on the amount of lysine and methionine in buckwheat. The protein, lysine, methionine contents $(25.3 \%(\mathrm{w} / \mathrm{w}), 58.8 \mathrm{~g} / \mathrm{kg}$, and $13.3 \mathrm{~g} /$ $\mathrm{kg})$ in TB bran were higher than that in CB bran $(21.6 \%$ (w/w), $54.7 \mathrm{~g} / \mathrm{kg}$, and $1.09 \mathrm{~g} / \mathrm{kg}$ ) (Bonafaccia et al. 2003). The fermentation process of buckwheat by $R$. oligosporus can increase the amino acid content in buckwheat, thus the L-carnitine contents in FTB are higher than that of FCB. The total phenolic contents in FCB and FTB were increased 2.4 times and 1.4 times compared to $\mathrm{CB}$ and TB. Among phenolic compounds in buckwheat, rutin and quercetin were considered as major bioactive compounds in buckwheat. There is a wide variation of rutin content in buckwheat seed depending on the species, variety, and

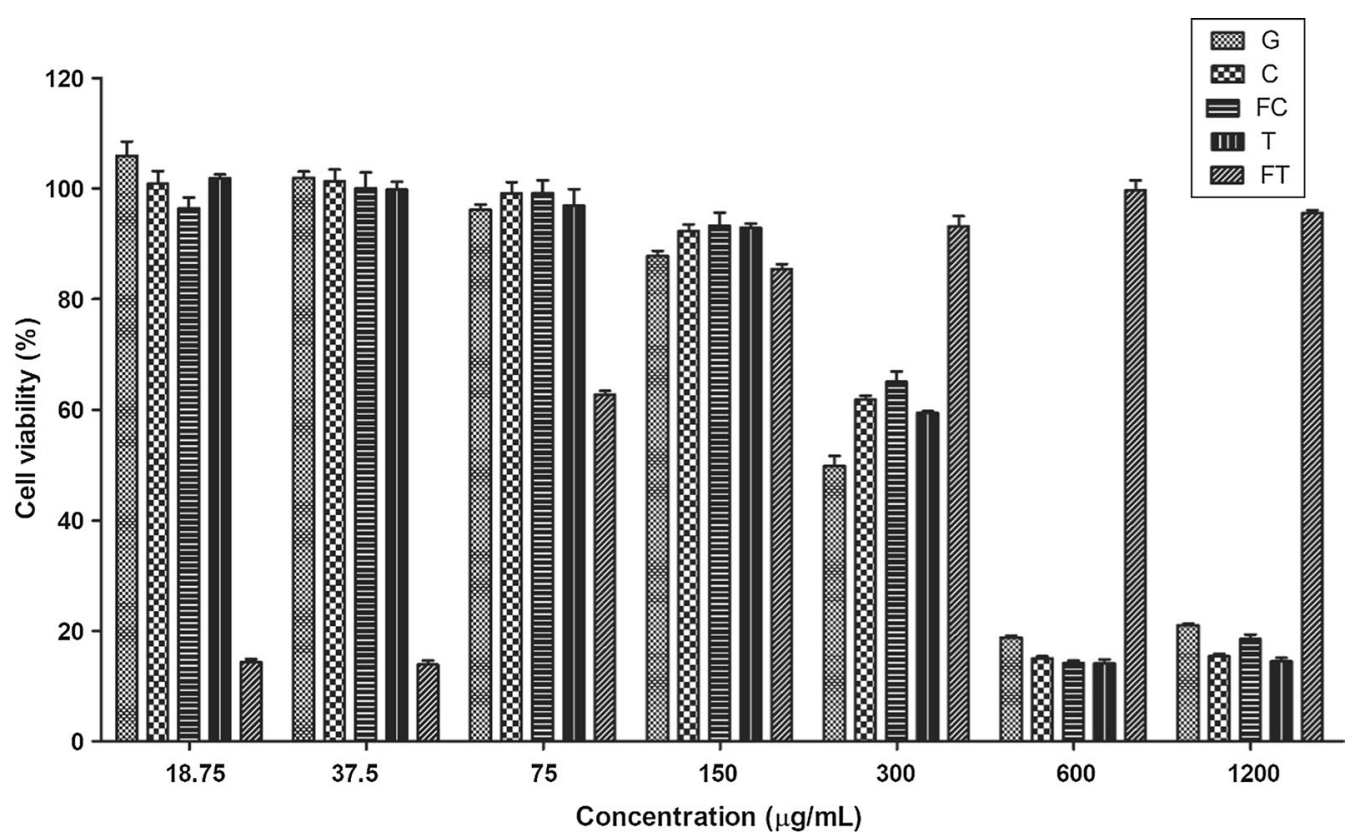

Fig. 2 Cell cytotoxicity of ethanol extracted oyster mushroom against Raw 264.7 cells. Ethanol extracted oyster mushroom grown up on $G$ basal medium, CB common buckwheat medium, FCB fermented common buckwheat medium, TB tartary buckwheat medium, FTB fermented tartary buckwheat medium against Raw 264.7 cells 
the environmental conditions under which they are produced (Jiang et al. 2007). Therefore, rutin and quercetin were selected in buckwheat and fermented buckwheat. Although quercetin contents in fermented buckwheat were decreased compared to non-fermented buckwheat, rutin contents in FTB was increased 1.3 times compared to TB. McCue and Shetty (2003) reported that $\alpha$-amylase and endogenous carbohydrate-cleaving enzymes produced from $R$. oligosporus can generate polyphenols from carbohydrate-conjugated phenolic compounds during fermentation of buckwheat. In addition, $R$. oligosporus is a known strain to produce $\beta$-glucosidase, $\beta$-glucuronidase and xylanase when it degrades the cell wall matrix (Huynh et al. 2014; Varzakas 1998). Thus, it probably metabolizes extracellular components with bioconversion of phenolic compounds by the fermentation that leads the cell-wall degrading enzymes to hydrolyze glycosidic bonds and produces unbound phenolics and aglycone forms. The fermentation processes releasing phenolic compounds from plant matrixes followed by the metabolic pathways of flavonoids: glycosylation, deglycosylation, ring cleavage, methylation, glucuronidation, and sulfate conjunction which are the ways of producing new bioactive compounds as well as increasing the total phenol contents and rutin contents in fermented buckwheat (Huynh et al. 2014).

Oyster mushroom grown on buckwheat and fermented buckwheat had higher L-carnitine contents than mushroom grown on normal medium (Table 3 ) and the L-carnitine contents in mushroom grown on FCB was similar to the amount of $\mathrm{L}$-carnitine in pork muscle (Demarquoy et al. 2004). L-carnitine content in oyster mushroom grown on fermented buckwheat medium was higher than mushroom grown on non-fermented buckwheat medium. It could be explained on the grounds that $R$. oligosporus can synthesize various L-carnitine derivatives that might be supplied to mycelia of oyster mushroom. Further study is needed to obtain clearer explanation. One of the reasons for the higher antioxidant activities of ethanol extracts from mushrooms grown on $\mathrm{CB}, \mathrm{TB}, \mathrm{FCB}$ and FTB medium compared to those of mushroom grown on G medium (Fig. 1) is the presence of L-carnitine which is known to possess antioxidant activity (Holasova et al. 2002).

The Raw 264.7 cell viability in the presence of ethanol extract from oyster mushroom grown on buckwheat medium was higher than that of oyster mushroom grown on $\mathrm{G}$ medium. It has been reported that L-carnitine can reduce oxidative stress in in vitro cell culture of Raw 264.7 cells and HK-2 cells (Koc et al. 2011; Ye et al. 2010). L-carnitine is also known to have anti-inflammatory activity because it can suppress inducible nitric oxide synthase (iNOS) that produces nitric oxide at transcriptional level (Koc et al. 2011). Therefore, the higher in
Raw 264.7 cell viability might be due to its higher content of L-carnitine. However, the pattern of L-carnitine concentration in mushroom was not exactly the same as that of mushroom extracts cytotoxicity against Raw 264.7 cells. Therefore, L-carnitine might not be the only factor involved in the less cytotoxicity of ethanol extract from oyster mushroom grown on buckwheat media. Further studies are needed to understand the underlying mechanisms.

\section{Additional file}

Additional file 1: Figure S1. DPPH radical scavenging activity of trolox.

\section{Abbreviations}

P. ostreatus: Pleurotus ostreatus; R. oligosporus: Rhizopus microspores var. oligosporus; TPC: total phenol content; TFC: total flavonoids content; G: basal; CB: common buckwheat; FCB: fermented common buckwheat; TB: tartary buckwheat; FTB: fermented tartary buckwheat; TSI: total size index; LC-ESI-MS: liquid chromatography-electrospray ionization-tandem mass spectrometry: DMSO: dimethyl sulfoxide; DPPH: 2,2-diphenyl-1-picrylhydrazyl; SC: scavenging activity; SEM: standard error of the mean; iNOS: nitric oxide synthase.

\section{Authors' contributions}

TL performed fermentation and drafted manuscript. TN carried out cell tests and preparation of revised manuscript. NP participated in antioxidant assay and growth of fungi. SK and JK performed buckwheat fermentation, preparation of extracts and component analyses. SJ and KS conducted mushroom component analyses and morphological characterization. JH and JC performed mushroom spawning, fruiting of mushroom in field scale and preparation of mushroom fruit body extract. DK designed and coordinated the study. All authors read and approved the final manuscript.

\section{Author details}

${ }^{1}$ Graduate School of International Agricultural Technology and Center for Food and Bioconvergence, Seoul National University, Pyeongchang 25354, South Korea. ${ }^{2}$ The Institute of Food Industrialization, Institutes of Green Bio Science \&Technology, Seoul National University, Pyeongchang 25354, South Korea. ${ }^{3}$ Mushroom Research Institute, GARES, Gwang-Ju, Gyeonggi 12805, South Korea.

\section{Acknowledgements}

Not applicable.

\section{Competing interests}

The authors declare that they have no competing interests.

\section{Availability of data and materials}

All data generated or analyzed during this study are included in this manuscripts.

\section{Consent for publication}

Not applicable.

\section{Ethics approval and consent to participate}

Not applicable. This paper does not contain any studies with human participants or animal performed by any of the authors.

\section{Funding}

This work was partially supported by the Basic Science Research Program through the National Research Foundation of Korea (NRF) funded by the Ministry of Education (NRF-2015R1D1A1A01056929; D. Kim), by Korea Institute of Planning and Evaluation for Technology in Food, Agriculture, Forestry (IPET) through Agriculture, Food and Rural Affairs Research Center Support Program, 
funded by Ministry of Agriculture, Food and Rural Affairs (MAFRA) (710012-031-HD220), under the framework of International Cooperation Program managed by the NRF (2016K1A3A1A19945059), and OTTOGI Corporation through Research and Publication Project.

\section{Publisher's Note}

Springer Nature remains neutral with regard to jurisdictional claims in published maps and institutional affiliations.

Received: 31 May 2018 Accepted: 17 August 2018

Published online: 27 August 2018

\section{References}

Akyuz M, Onganer AN, Erecevit P, Kirbag S (2010) Antimicrobial activity of some edible mushrooms in the eastern and southeast Anatolia region of Turkey. Gazi Univ J Sci 23(2):125-130

Bonafaccia G, Marocchini M, Kreft I (2003) Composition and technological properties of the, flour and bran from common and tartary buckwheat. Food Chem 80(1):9-15

Bremer J (1983) Carnitine-metabolism and functions. Physiol Rev 63(4):1420-1480

Cave MC, Hurt RT, Frazier TH, Matheson PJ, Garrison RN, McClain CJ, McClave SA (2008) Obesity, inflammation, and the potential application of pharmaconutrition. Nutr Clin Pract 23(1):16-34

Chang CC, Yang MH, Wen HM, Chern JC (2002) Estimation of total flavonoid content in propolis by two complementary colorimetric methods. J Food Drug Anal 10(3):178-182

Chao A, Thun MJ, Connell CJ, McCullough ML, Jacobs EJ, Flanders WD, Rodriguez C, Sinha R, Calle EE (2005) Meat consumption and risk of colorectal cancer. JAMA 293(2):172-182

Choi J-i, Ha T-m, Jeon D-h, Ju Y-c, Cheong J-c (2013) Characteristics and breeding of a long-term storable oyster mushroom (Pleurotus ostreatus) variety. J Mushroom Sci Prod 11(3):149-153

Choi ES, Kang YY, Mok H (2018a) Evaluation of the enhanced antioxidant activity of curcumin within exosomes by fluorescence monitoring. Biotechnol Bioproc Eng 23(2):150-157

Choi MH, Jo HG, Kim MJ, Kang MJ, Shin HJ (2018b) Fruit juice supplementation alters human skin antioxidant levels in vivo: case study of Korean adults by resonance raman spectroscopy. Biotechnol Bioproc Eng 23(1):116-121

da Silva MCS, Naozuka J, da Luz JMR, de Assuncao LS, Oliveira PV, Vanetti MCD, Bazzolli DMS, Kasuya MCM (2012) Enrichment of Pleurotus ostreatus mushrooms with selenium in coffee husks. Food Chem 131(2):558-563

De Vivo D, Tein I (1990) Primary and secondary disorders of carnitine metabolism. Int Pediatr 5(2):134-141

Demarquoy J, Georges B, Rigault C, Royer M-C, Clairet A, Soty M, Lekounoungou S, Le Borgne F (2004) Radioisotopic determination of L-carnitine content in foods commonly eaten in Western countries. Food Chem 86(1):137-142

Fabjan N, Rode J, Kosir IJ, Wang ZH, Zhang Z, Kreft I (2003) Tartary buckwheat (Fagopyrum tataricum Gaertn.) as a source of dietary rutin and quercitrin. J Agric Food Chem 51(22):6452-6455

FAOSTAT (2016) Mushroom and truffle. Rome: Food and Agriculture Organization of the United Nations. http://www.fao.org/faostat/en

Holasova M, Fiedlerova V, Smrcinova H, Orsak M, Lachman J, Vavreinova S (2002) Buckwheat-the source of antioxidant activity in functional foods. Food Res Int 35(2-3):207-211

Huynh NT, Van Camp J, Smagghe G, Raes K (2014) Improved release and metabolism of flavonoids by steered fermentation processes: a review. Int J Mol Sci 15(11):19369-19388

Jesenak M, Majtan J, Rennerova Z, Kyselovic J, Banovcin P, Hrubisko M (2013) Immunomodulatory effect of pleuran ( $\beta$-glucan from Pleurotus ostreatus) in children with recurrent respiratory tract infections. Int Immunopharmacol 15(2):395-399

Jiang P, Burczynski F, Campbell C, Pierce G, Austria JA, Briggs CJ (2007) Rutin and flavonoid contents in three buckwheat species Fagopyrum esculentum, F-tataricum, and F-homotropicum and their protective effects against lipid peroxidation. Food Res Int 40(3):356-364

Koc A, Ozkan T, Karabay A, Sunguroglu A, Aktan F (2011) Effect of L-carnitine on the synthesis of nitric oxide in RAW 264. 7 murine macrophage cell line. Cell Biochem Funct 29(8):679-685

Kristensen HL, Rosenqvist E, Jakobsen J (2012) Increase of vitamin D(2) by UV-B exposure during the growth phase of white button mushroom (Agaricus bisporus). Food Nutr Res 56:7114

Lee Y-H, Chi J-H, Kim Y-H, Yu S-H (1999) Comparison in productivity of Pleurotus ostreatus sawdust spawn under different storage conditions. Korean $J$ Mycol 27(5):319-321

Maxwell T, Lee KS, Chun SY, Nam KS (2017) Mineral-balanced deep sea water enhances the inhibitory effects of chitosan oligosaccharide on atopic dermatitis-like inflammatory response. Biotechnol Bioproc Eng 22(2):120-128

McCue P, Shetty K (2003) Role of carbohydrate-cleaving enzymes in phenolic antioxidant mobilization from whole soybean fermented with Rhizopus oligosporus. Food Biotechnol 17(1):27-37

Mota C, Santos M, Mauro R, Samman N, Matos AS, Torres D, Castanheira I (2016) Protein content and amino acids profile of pseudocereals. Food Chem 193:55-61

Nguyen TTH, Si J, Kang C, Chung B, Chung D, Kim D (2017) Facile preparation of water soluble curcuminoids extracted from turmeric (Curcuma longa L.) powder by using steviol glucosides. Food Chem 214:366-373

Novakova K, Kummer O, Bouitbir J, Stoffel SD, Hoerler-Koerner U, Bodmer M, Roberts P, Urwyler A, Ehrsam R, Krähenbühl S (2016) Effect of L-carnitine supplementation on the body carnitine pool, skeletal muscle energy metabolism and physical performance in male vegetarians. Eur J Nutr 55(1):207-217

Pan A, Sun Q, Bernstein AM, Schulze MB, Manson JE, Willett WC, Hu FB (2011) Red meat consumption and risk of type 2 diabetes: 3 cohorts of US adults and an updated meta-analysis. Am J Clin Nutr 94(4):1088-1096

Park N, Lee TK, Nguyen TTH, An EB, Kim NM, You YH, Park TS, Kim D (2017) The effect of fermented buckwheat on producing L-carnitine- and gammaaminobutyric acid (GABA)-enriched designer eggs. J Sci Food Agric 97(9):2891-2897

Sánchez C (2010) Cultivation of Pleurotus ostreatus and other edible mushrooms. Appl Microbiol Biotechnol 85(5):1321-1337

Sarangi I, Ghosh D, Bhutia SK, Mallick SK, Maiti TK (2006) Anti-tumor and immunomodulating effects of Pleurotus ostreatus mycelia-derived proteoglycans. Int Immunopharmacol 6(8):1287-1297

Singleton VL, Orthofer R, Lamuela-Raventós RM (1999) Analysis of total phenols and other oxidation substrates and antioxidants by means of folin-ciocalteu reagent. Methods Enzymol 299:152-178

Steiber A, Kerner J, Hoppel CL (2004) Carnitine: a nutritional, biosynthetic, and functional perspective. Mol Aspects Med 25(5):455-473

Varzakas T (1998) Rhizopus oligosporus mycelial penetration and enzyme diffusion in soya bean tempe. Proc Biochem 33(7):741-747

Venkatakrishnan V, Shenbhagaraman R, Kaviyarasan V, Gunasundari D, Radhika K, Dandapani R, Jagadish LK (2009) Antioxidant and antiproliferative effect of Pleurotus ostreatus. J Phytol 2(1):22-28

Vieira PAF, Gontijo DC, Vieira BC, Fontes EAF, de Assuncao LS, Leite JPV, Oliveira MGD, Kasuya MCM (2013) Antioxidant activities, total phenolics and metal contents in Pleurotus ostreatus mushrooms enriched with iron, zinc or lithium. Lwt Food Sci Technol 54(2):421-425

Wang Y, Beydoun MA (2009) Meat consumption is associated with obesity and central obesity among US adults. Int J Obesity 33(6):621-628

Wolff ERS, Wisbeck E, Silveira MLL, Gern RMM, Pinho MSL, Furlan SA (2008) Antimicrobial and antineoplasic activity of Pleurotus ostreatus. Appl Biochem Biotechnol 151(2):402-412

Ye J, Li J, Yu Y, Wei Q, Deng W, Yu L (2010) L-carnitine attenuates oxidant injury in HK-2 cells via ROS-mitochondria pathway. Regul Pept 161(1):58-66

Zhang ZL, Zhou ML, Tang Y, Li FL, Tang YX, Shao JR, Xue WT, Wu YM (2012) Bioactive compounds in functional buckwheat food. Food Res Int 49(1):389-395 